late editions of what are regarded as standard works on the subject of fractures shows that this injury is not even mentioned.

In his recent study of fractures of the upper extremity I am glad to see Mr. Platt gives it proper notice, for, as Professor Bennett has pointed out, not only does it somewhat simulate a dislocation in the living subject, but the pain and swelling that accompany it so mask crepitus that the injury is generally regarded as a "sprain of the thumb." It is true that, even if untreated, the fracture unites with a trivial deformity after all, but at the same time a hand so injured "remains under the best of treatment long disabled, and without treatment for a greatly longer time" (Bennett). This statement receives confirmation from the following case, which is also of interest in that the skiagraph I took of the injury corroborates in every detail Professor Bennett's original description of it, and, further, in that the accident happened to a medical man, who had simply regarded his right thumb as being " badly bruised."

When I first saw the patient 16 days had elapsed since the accident, which had been caused by a fall during rough weather down the stairs leading to the cabin of the steamer on which he was acting as surgeon. When he fell the terminal phalanx of the right thumb happened to be flexed on the first phalanx, and he struck the point of this latter against a projecting bit of woodwork. As he said, he thought he had severely bruised his thamb, and the only treatment used was hot bathing and a soothing liniment, but recovery was so slow that he consulted me on his return to Glasgow.

Even after the lapse of 16 days I thought I could still detect some crepitus, and an $x$-ray photograph confirmed the existence of a fracture of the base of the first metacarpal bone.

Reference to Fig. I shows that the fracture there depicted is exactly that described by Professor Bennett. It is oblique, detaching the palmar half or more of the articular surface of the metarcarpal bone facing the trapezium; while, in addition, the entire metarcarpal bone, except the little piece so separated, has slipped backwards, no doubt through the action of the extensor ossis metacarpi, and thus simulates a subluxation of the bone in this direction. Both these points are clearly brought out in the skiagraph.

It may be as well to allude here to the kind of disablement which this fracture causes, especially as it is very well illus. trated by this case. Summed up briefly, the leading feature of it is the inability to oppose the thumb to the index finger. It was interesting to hear from the patient in how many ways this was felt. Thus, while dressing he found he could not button his collar stud, nor could he make a bow on his tie. He could grasp his boot lace and push it through the eyelet holes, but he could not pull it through. He could hold a pair of scissors but he could not cut his nails, nor could he pick up a pin off the table. When washing his face he could only do so with the palm of his hand, as, owing to the pain it caused, he had to keep off the ball of the thumb. Again, being a smoker he found he could hold a match but he could not strike it. At the piano he could with difficulty stretch an octave, and he could not come down on the notes with any force. Writing, too, was out of the question, and profession. ally he was very much handicapped, for though he could hold a bistoury he could not make an incision with it. These illustrations indicate how much such an injury cripples the hand, and how much it is felt in many of the little details of every. day life. The cause of this injury is usually some force ap. plied directly to the point of the thumb, as when the carpenter in using his plane strikes against any obstacle, or when a person falls and the end of the digit comes in contact with the ground. The treatment of these cases is to extend and fully abduct the thumb, retaining it in this position by a suitable apparatus. This was what was done in the present case. I extended and fully abducted the thumb, and when it was in that position I moulded a poroplastic splint to it. After two and a half weeks of treatment I took another skiagraph (Fig. 2), and it shows how satisfactory has been the apposition of the fragments as well as the reposition of the displaced metacarpal bone on to the trapezium. By this time, too, there was a decided improvement in the usefulness of the hand. Later on all disablement quite passed away, and the patient resumed his duties as surgeon on a large steamer.
This case illustrates well the practical utility in surgical work of the Roentgen rays, and it teaches the lesson that all so-called "sprains of the right thumb" should be subjected to them, as otherwise a "Bennett's fracture" is liable to be overlooked.

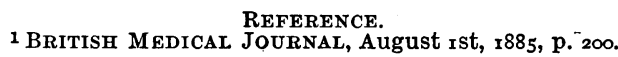

\section{A CASE OF FRACTURE DISLOCATION OF THE SPINE,}

WITH COMPLETE DESTRUCTION OF THE CORD IN THE UPPER LUMBAR REGION.*

By ASHLEY W. MACKINTOSH, M.A., M.D., Assistant Physician, Aberdeen Royal Infirmary.

ALthough so much attention has been given to the subject within recent years-notably by Ross, Thorburn, Starr, Head, Sherrington, Bruns, and Kocher-there is still no certainty as to the exact localisation of the motor and sensory functions of the various cord segments and spinal roots. It seems therefore desirable that all cases bearing on the subject should be put on record, especially those in which it was possible to obtain not only an accurate clinical record, but also an exact knowledge of the site and extent of the lesion as shown by a necropsy. Last year ${ }^{1}$ I gave in the British MEdical JournaL the notes of a case of spinal caries, and drew therefrom some deductions as to the distribution of certain sensory spinal roots. On the present occasion, as on the last, I have to express my great indebtedness to Professor Ogston for affording me every opportunity of observing and recording a most interesting case of spinal lesion. A comparison of the two cases is instructive, as the spinal roots affected are very much the same in both, whereas the deductions to be drawn as to the sensory localisation of certain root areas seem to be different; whether it is impossible to reconcile the two will be considered later.

The following is an abstract of the notes of the case of fracture dislocation of the spine which is the subject of the present paper :

A strong. healthy man, aged 32, as the result of a fall, showed depression of the eleventh dorsal spine and prominence of twelfth dorsal and first lumbar spines. From the onset complete paraplegia; lower limbs quite flaccid and reftexes abolished (knee-jerks, plantar, and cremasteric); loss of sensation of all forms on legs and lower trunk, on right side up to level of umbilicus, and on left side two and a-half inches lower; upper limit of total analgesia and thermoancethesia higher and sharper than that of total ancsthesia; a zone of incomplete anasthesia; marked constipation and incontinence of fixces; reflex or intermitlent incontinence of urine, with imperfect emptying of bladder. During course of illness, rapid wasting and loss of faradic excitability in all leg muscles; vasomotor and trophic changes in ancesthetic area; cystitis and, later, diminution in capacity of bladder and simple dribbling of urine; uramic symptoms; death in three and a-half months.

Necropsy: Fracture dislocation of the eleventh and tuelfth dorsal vertebrx; complete division of cord below origin of twelfth dorsal roots; destruction of upper three (or four) lumbar segments : sacral cord much compressed and dis integrated; eleventh intervertebral foramen on right side obliterated by callus ; both twelfth dorsal posterior roots; anterior sacral roots considerably de-

generated.

J. S., aged 32 , a strong and healthy man, fell over a railway cutting, about 30 feet deep, at 8 P.M. on August 29 th, 1897. He was admitted into the A

He was found on admission to be in a state of extreme collapse and He was found on admission to be in a state of extreme collapse and
partially insensible, probably due partly to concussion and partly to alcohol; the temperature was subnormal, and the radial pulse almost imperceptible. There was a compound fracture of the left humerus, and a deformity of the spine in the lower dorsal region. The legs were completely paralysed and flaccid, and the lower half of the body quite dnæspletely paralysed and flaccid, and the

On August 3 ist he had recovered complete consciousness, and a more minute examination could be made, which revealed the following conditions :

There was swelling and ecchymosis in the neighbourhood of the eleventh and twelfth dorsal and first lumbar spines, and an abraded contusion to the left of the eleventh dorsal spine and another over the sacrum. The eleventh dorsal spine was depressed, the twelfth dorsal and first lumbar spines prominent. There was absolute paralysis of the legs, which were quite flaccid; the abdominal muscles were very flabby. Patient did not complain of any pain. Objectively, sensation of all forms was found to be abolished on the legs and lower part of the trunk : the upper limit of loss of the various forms of sensation followed very much the same lines as those given later in detail, and figured (Fig. r), except that, on the right side intact sensation of all forms were noted to extend for about an inch beneath the umbilicus. * Read before the Aberdeen, Banff, and Kincardine Branch of the British 
There was no girdle sensation or zone of hyperæsthesia, and no appreciation of the position of the lower limbs or of their passive movement. On passing a catheter there was no sensation in the urethra or in the bladder, and sensation in the rectum was also absent. There were no knee-jerks and no ankle clonus; the plantar and cremasteric relexes were also absent, the epigastric reflexes well marked. Patient had no control over the bladder and rectum; if the bladder was allowed to distend it reached a point when a gush of urine came, turther dribbling. About 5 ounces of urine were always left in the bladder after each gush. The patient was not conscious of the need of micturition when the bladder was distended. There was no priapism. There was a tenden

The patient was catheterised regularly, and his condition remained unchanged-the temperature normal and urine acid-till September roth, when it was noted that the legs had wasted considerably, and the temperature began to fluctuate, reaching usually $99.5^{\circ}$ to Ior $^{\circ} \mathrm{F} \cdot$ in the desquamation of the skin over the anæsthetic area; the abrasion on the sacrum showed no sign of healing. Signs of cystitis now appeared; the urine became alkaline and turbid, and deposited pus and phosphates. The bladder was washed out with antiseptic lotions, but although the urine occasionally showed signs of improvement, the tendency to cystitis remained to the end.

On September 14 th patient complained of a pain over the right false ribs, and, two weeks later, of a girdle-like pain on the right side, a little felt a "fluttering" sensation running down his legs, which were still quite anæsthetic.

On October roth it was noted that the legs had wasted very greatly. The patient had now some vague sensation in or about the bladder $;$ he knew when it was distended, and felt pain over the region of the bladder when the urine was being drawn off; he seemed even to have some slight perception of the presence of a catheter when it was moved about in the bladder.

Towards the end of October, when I saw the patient for the first time, his condition was as follows:

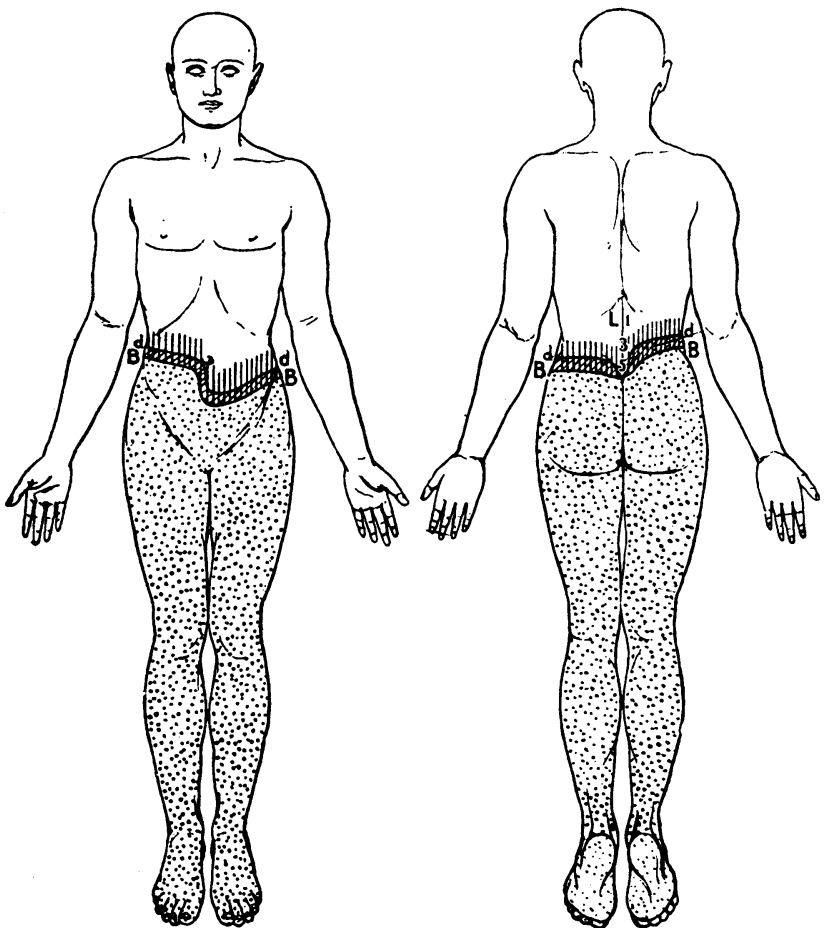

Fig. 1.-The dotted portion denotes total anesthesia, analgesia, and thermo-anæsthesia. /// denotes total analgesia and thermoanæesthesia. IIII denotes imperfect tactile sensibility. L $1,3,5$ denote the level of the corresponding lumbar spines. The zone $d B$ is $\frac{3}{4}$ inch wide. The line BB denotes the upper limit of total anæsthesia. The line dd denotes the upper limit of total analgesia level of the umbilicus on the right side, and $2 \frac{1}{2}$ inches lower on the left side.

The eleventh dorsal spine was depressed, the twelfth dorsal and first lumbar spines prominent; there was no special point of tenderness on deep pressure, but the whole prominence was more or less tender. There was marked wasting of all the muscles of the legs, which were absolutely flaccid, and gave no reaction to faradism. The knee-jerks, plantar and cremasteric reflexes were absent; the epigastric reflexes were present on both sides, more actively on the left. On the right side no abdominal reflex could be elicited below the level of the umbilicus, while on the left
side a distinct reflex was got on stroking the abdomen as low as the upper limit of analgesia (See below). The condition of the sphincters remained as noted on August 3 Ist. Constipation had been marked throughout. There was marked vasomotor affection of the legs and lower part of the abdomen; the bright red line of hyperæmia obtained on scoring with the and lower part of the abdomen, as shown in Fig. 1

Sensations of Pain. Heat, and Cold. - There was an absolutely sharp linedd-up to which there was complete analgesia and thermo-anæsthesia, while above this line the sensations of pain and temperature seemed quite intact. On the right side this line-dd-started in the middle line from the umbilicus, sloped slightly upwards so as to reach within half an inch of the tenth rib, and ran round to the back at the level of the third lumbar spine, dipping down somewhat near the middle line. On the left side the line occupied a lower level: it started in the middle line in front at a point $2 \frac{1}{2}$ inches beneath the umbilicus, ran outwards and very slightly
upwards just above the crest of the ilium, and dipped down posteriorly
at the level of the fifth lumbar spine.

Sensation of Touch.-The upper limit of total anæsthesia was demarcated by a tolerably sharp line, $\mathrm{BB}$, not quite so sharp as the upper limit of analgesia and thermo-anæsthesia. This line BB ran parallel to the line da Above the line BB there was a zone about two inches in breadth, over which there was defective sensation of touch, and theire was no absolutely sharp line separating this zone from the part above where sensathe zone dB he felt the touch of a pin or test tube, but had no painful or thermal sensation.

The sense of position or of passive movement was entirely absent_in the legs.

There was no zone of hyperæsthesia at the upper limit of the anæsthetic rea, and patient did not complain of pain or girdle sensation.

About the beginning of November the condition of the bladder began to alter. Its capacity diminished very much, so that from November inth onwards only 3 ounces of lotion could be introduced; if an attempt was

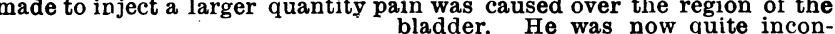

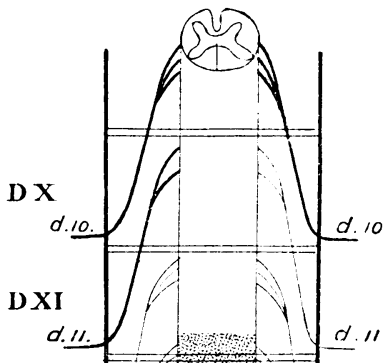
almost continuously without distending the bladder; the urine became very thick and turbid, deposited a arge amount of pus and phosphates, and had a foul ammoniacal odour. The temperature began to fluctuate very much, sometimes reaching $102^{\circ} \mathrm{F}$. in the evening, sometimes being normal. On December rst the total quantity of urine began to diminish ; the dribbling continued; the catheter drew off less than 2 ounces of very foul urine, and only the same amount of lotion could be introduced. On December 3 rd the patient became drowsy and apathetic, uræmic symptoms deepened. The DXII 112 . DXII 112 . DXII 112 .

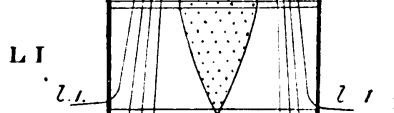
months after the accident.

\section{NECROPSY.}

Only a very partial and hurried necropsy was permitted, and, by the kind permisson or professor J. Stewart Milne and myself on De. Stewarth It confirmed the concember 13 th. It confrmed the conthe spinous processes, which were depressed and prominent, the eleventh dorsal being depressed, the twelfth dorsal and first lumbar prominent. When the spinal canal was opened it was seen that the cord was completely divided, and the ends-separated by about an inch-were connected only by dura mater. The upper segment of the cord ended bejow at the lower border of the body of the eleventh dorsal vertebra, while the lower segment began opposite the middle of the body of the twelfth dorsal vertebra (Fig. 2) The remains of a large extradural bloodclot lay over the
back of the cord opposite the twelfth
dorsal and first lumbar bodies. The dorsal and first lumbar bodies. The eleventh dorsal vertebra was dislocated forwards and to the left (Figs. 2 and 3 ) carrying with it an oblique fragment of the left half of the upper segment of the body of the twelth dorsal vertebra, the body of the twelfth dorsal being fractured in an obliquely transverse manner and cancellous tissuo of the body much jocted into the jected into the canal. Onth goral vertebra the uper segment of the cord tebra, the upper segment of the cord (about three-quarters of an inch) and to 
the left;of the lower segment of the cord, the dura mater which joined the two segments thus running posteriorly and to the right over the spicular upper part of the body of the twelfth dorsal vertebra. The dura mater round the lower end of the upper segment of the cord was firmly adherent to the bone as far up as the origin of the ninth dorsal roots. There was also a perpendicular fracture (Fig. 3) involving tbe posterior parts of the bodies of the twelfth dorsal and first lumbar vertebræ, and running about half an inch anterio-posteriorly through the bodes. The effect or this perpendicular fraction and narrow antero-posteriorly the spinal canal at this part, and the cord Dr. Dr. Milne, the eleventh dorsal nerve was seen to issue apparently quite vertebral foramen was completely obliterated by callus (Fig. vertebral foramen was completely obliterated by callus (Fig. 3). Firm bony union of the parts had taken place, a good deal of callus being in a state of consecutive nephritis, parts suppurating, parts quite gaigrenous.

The spinal cord was preserved in Müller's fluid, and, after being sufficiently hardened, it was examined more carefully both macroscopically and microscopically. Fig. 4 is a scheme designed to show diagrammatically the condition found as regards the cord and posterior roots

NOTES OF MACROSCOPIC EXAMINATION.-There is complete absence of cord substance for a distance of apparently about an inch; it is probable however, that considerably less than an inch of the cord is destroyed, as the parts here were seen at the necropsy to be so stretclied. The two segments of the cord are connected only by dura mater, continuous with that covering the posterior part of the

Examination of the seg ment of the cord above dura mater is that the and its outer surface rough ithat is surface was adherent to there it canal) as far un bo origin of the ninth dor sal roots, a distance of 8 $\mathrm{cm}$.; the dura is ever, not adherent to the cord except in its lower half-inch, where it cann be separated from the cord without tearing. The lowest roots which. Th be seen leaving the cord are the twelfth dorsal they issue from the cord end, and descend inside the dura to become im plicated in the cicatricial mass at the lower end of the upper segment of the cord ; they cannot be traced further. The eleventh dorsal root leave the cord $4 \mathrm{~cm}$ above the site of lesion, and descend inside the dura to pierce it just above the lower end of the cord ; on the righ side the eleventh. dorsa posterior root seems disthety smaller than on in lert side, and is lost the adhesions between while on and the cord, is seen to pierce thide it and issue quite normally. The tenth dorsal roots pierce the dura about $2 \frac{1}{2} \mathrm{~cm}$. above the site of ous levels shows to the naked eye well-marked ascending degeneration. The segment of the cord below the lesion is evidently very much com pressed and flattened antero-posteriorly. The coccygeal and all five sacral roots appear of fairly normal size ; the same is true of the fifth lumbar roots, which leave the cord just below its upper and. The fourth lumbar roots are very much smaller than the fifth, and the upper three lumbar roots ane mere threads: all these, when traced upwards, get lost in the cicatrix at the upper end of the cord. Thus, the part of the cord which is destroyed is that which gives origin to the upper three (or four) lumbar roots.

NOTES OF THE Microscopic Examination.-Sections of the cord at different levels were stained with Wiegert-Pal's hæmatoxylon, Marchi's osmic acid method, methylene blue, and eosin, etc. In the upper segment of the cord there is splendidly-marked ascending degeneration, but, apart from this, nothing abnormal can be detected except a few small, scattered patches, apparently myelitic in origin, lying in the white matter, mainly on the lateral aspects of the anterior horns; these are seen in sections as high as the level of origin of the twelfth dorsal roots, but they quite cease above that level. By Marchi's method the twelfth dorsal posterior roots are seen to be quite degenerated on both sides; the same is true of the right eleventh, while there is no trace of degeneration in the left eleventh, and the tenth and higher roots are quite intact on both sides. The lower segment of the cord, as shown by Marchi's method, is so degenerated at
The cord is also very much deformed, being compressed anteroposteriorly ; this is specially seen at the level of the third and fourth sacral roots, where the central part of the cord is much disintegrated There is well-marked degeneration in the anterior roots of all the sacral nerves, while the posterior roots show only slight traces of degeneration

REMARKS.

In attempting to arrive during life at a diagnosis of the nature, site, and extent of the spinal injury in this case, the first conclusion drawn was that there was a complete transverse lesion of the spinal cord. The complete and permanent anæsthesia of all parts below the site of the bony lesion, and the absence of paræsthesia or hyperæsthesia on the anæsthetic area seemed to point distinctly to this conclusion, while the flaccid condition of the leg muscles and abolition of the reflexes, although somewhat equivocal in their significance ( $v$. infra), were regarded as being in favour of the same view. In the light of the necropsy, which proved beyond doubt that this view was correct, it is not easy to explain satisfaetorily the later observations, that patient sometimes felt a "fluttering" sensation running down his legs, and had some vague sensations about the blai der, that is, he knew when it was distended, and felt some pain over it when the urine was being drawn off, and later, when fluid was introduced, and he seemed even to have some slight perception of the presence of a catheter when it was moved about. For the "fluttering" sensation in the legs I can suggest no other explanation than that it was due to irritation of the corresponding sensory fibres in the upper segment of the cord, probably from contraction of the cicatrix at its lower end. The vague bladder sensations cannot have been related to the sensory nerves which supply the mucous membrane of the bladder, as they arise from the cord far below the site of complete transverse division of the cord (probably second, third, and fourth sacral segments). Head ${ }^{4}$ finds that in over distension of the bladder (for example, from stricture), and consequent straining against the obstruction, pain is diffused as high as the distribution of the eleventh dorsal segment the bladder sensations in the case of J.S. may have been, at least partly, of this nature, and perhaps also partls due to the condition of cystitis and its effects on adjacent structures, for example, ureters and kidneys, which could cause pain to be referred along roots lying above the lesion.

In trying to form some idea of the site and extent of the lesion, we considered (I) the manifest spinal deformity, (2) the height to which the conducting functions of the cordnamely, motion and sensation-were abolished, and (3) the extent of the cord along which the central functions, especially muscular nutrition and reflexes, were affected. The upper limit of any cord lesion is determined mainly by the second point mentioned, namely, the height of the muscular paralysis and anæsthesia, taken in conjunction with the position of girdle pains or zone of hyperæsthesia, which point to irritation of the lowest sensory roots leaving the cord above the 
site of lesion; these were strikingly absent throughout the greater part of the course of our case. It is manifestly difficult to tell to what level muscular paralysis extends on the trunk, and hence in cases of lesion of the dorsal cord we depend mainly on the height of the anæsthesia.

The relation of the upper limit of anæsthesia to the level of the bony lesion varies very considerably. It is a well-known fact, and one of importance to surgeons, that in the great majority of cases the upper limit of anæsthesia is distinctly below the level of the bony lesion. There are, at least, two reasons for this: (1) In a compression or crush the cord often suffers, while the roots, being firmer and more resistant, escape; the upper limit of anæsthesia will then be below the level of the crush by the length, at least, of the intravertebral course of the roots which arise from the cord above the crush but leave the canal below it.*

2. In many cases of crush of the cord, especially where very severe, the roots suffer as well as the cord; the roots may suffer close to and along with the cord, or' at their exit through the intervertebral foramina-the latter was the case with the right eleventh dorsal root in the case of $J$. $S$. The upper limit of anæsthesia will then be relatively higher, corresponding to the highest root implicated. Even in this second group of cases, however, the level of anæsthesia is usually well below the level of the crush : thus in the dorsal region it will be found to be three or four spines lower than the point of exit of the highest intercostal nerve involved; in the case of J. 8., for instance, the eleventh dorsal root was implicated on the right side, yet the anæsthesia did not extend higher than the third lumbar spine. This difference of level is sufficiently explained by the researches of Sherrington ${ }^{6}$, who found experimentally, by section of the posterior roots, that the areas of cutaneous supply of the posterior roots over-

lap so enormously that each cutaneous area is supplied by two or even three sensory roots. Thus in a crush affecting the roots there will not be complete anæsthesia up to the upper limit of the region supplied by the highest root involved, as sensation in that area will be supplied, at least in part, by the root (or roots) higher up.

In a few cases a high level of anæsthesia has been found to be due to myelitis, or more often hæmorrhage-the result of the trauma-extending along the cord above the level of the bony lesion.

Now, in the case of J. S., the spinal deformity showed that the eleventh dorsal vertebra was dislocated forwards, and, as total fracture dislocation is commonest at the lower dorsal vertebræ (Kocher), one was not surprised to find at the necropsy that there was also fracture of the twelfth dorsal * In this connection it is important to remember that, as Professor vertebræ varies very considerably. this will help to explain the varying levels of anæsthesia found in different cases in which the bony lesion appears identical. vertebra. Thecord is usually bruised and compressed by the lower fragment (Gowers ${ }^{3}$, p. 283), hence our conclusion was that the upper limit of lesion of the cord lay not higher than opposite the interval between the bodies of the eleventh and twelfth dorsal vertebræ. A glance at the diagram framed by Gowers ${ }^{3}$ (p. 200) to indicate the relations of the origin of the several nerve roots to the bodies of the vertebræ (these are followed in Fig. 4,q.v.) will show that this level corresponds to the origin of the first lumbar roots. So far, then, as the crush of the cord itself was concerned, one would not have expected the anæsthesia to extend higher than the region of distribution of the first lumbar roots; this was 80 in a case recorded by Thorburn 7 (Case XxvirI, p. 74) in which the spinal deformity was very similar to that of $\mathrm{J}$. $\mathrm{S}$. Oppenheim ${ }^{2}$ (p. 211), indeed, says that, "as a rule," in fracture of the twelfth dorsal vertebra, and sometimes in luxation of the eleventh, the uppermost lumbar segments are spared.

In the case of J. S., however, the anæsthesia reached the level of the umbilicus on the right side and somewhat lower on the left side. The relation of the umbilicus to the cutaneous areas supplied by the spinal segments or posterior roots is uncertain, and, quite provably, is variable ; Head places it as high as the junction of the ninth and tenth dorsal fields, and the case of spinal caries recorded by me ${ }^{1}$ supports this view; Gowers ${ }^{3}$ (page 270) sayg it " corresponds to the tenth dorsal nerves ;" Kocher ${ }^{8}$ shows it opposite the middle of tenth ; while Quain places it between the tenth and eleventh; and Thorburn $^{9}$ (page 368 ) is inclined to adopt this view, and thinks it lies " certainly no higher than the low. est part of the tenth." Even if the view were adopted that the umbilicus lay as low as the eleventh dorsal field, it was evident that the anæsthesia in the case of J. S. was too high to be explained by a lesion of the cord which did not extend higher

than the first lumbar segment: much more so, if the higher position of the umbilicus relatively to the dorsal cutaneous fields was accepted. In order to explain the high position of the anæsthesia two alternative views suggested themselves: either that the spinal roots were affected simultaneously with the cord, and higher on the right side than on the left, or that there was-as often happens in crushes of the cord-a bæmorrhage into the cord, extending above the level of the crush, especially on the right side. I do not knew any certain point of distinction between these two conditions, but I inclined to the latter and-as the necropsy showed-erroneous view from these two conditions : (I) the marked absence of root symptoms (for example, girdle pain or byperæsthesia) throughout the greater part of the course of the case, and (2) the exactness of demarcation of the upper limit of analgesia and thermoanæsthesia; both Head ${ }^{1}$ and Thorburn ${ }^{9}$ believe there is evidence to show that the cutaneous areas supplied by the spinal segments are more sharply defined than are the root areas ; and, indeed, the absence of overlapping of his areas is Head's main reason for believing that they correspond to 
the supply of spinal segments and not of posterior roots. The necropsy, however, leaves no possibility of doubt that the upper limit of anæsthesia in the case of J. S. was a root anæsthesia, and Fig. I-which was repeatedly confirmedmay be taken as a tolerably accurate representation of the state as regards impairment of sensation, caused by a lesion whose upper limit on the right side was the eleverth dorsal root and on the left side the twelfth dorsal root. This statement, however, in view of Sherrington's researches, ${ }^{6}$ does not imply that the upper limit of the cutaneous supply of the eleventh dorsal root is, as the chart shows, at the level of the umbilicus, and that of the twelfth dorsal root $2 \frac{1}{2}$ inches lower but the case is interesting, as it shows with remarkable clearness, in the difference of the levels of the anæsthesia on the two sides, the effect of abolition of function of the eleventh dorsal root. With regard to the position of the umbilicus relatively to the root areas, this case would point to its occupying a high position, at least as high as the junction between the tenth and eleventh dorsal areas. On the other hand, the case of spinal caries ${ }^{1}$ recorded by me seemed to point to a distinctly higher position of the umbilicus; there was pressure on the eleventh and twelfth dorsal roots, which were much atrophied, and the upper limit of anæsthesia was 2 inches beneath the umbilicus, so that the deduction drawn was that the area supplied by the eleventh dorsal root did not reach so high as the umbilicus. Such discrepancies in he localisation of the umbilicus have been noted before, and may be, as Thorburn" says, "dependent upon details of anatomy." It is, however, worthy of note that the character of the lesion was different in the two cases, and it is not impossible that this may explain the difierence in the level of the anæsthesia. In the case of spinal caries the damage was slowly produced by pressure, and in such cases it is notoriously difficult to draw any certain conclusion from the persistence of sensation, or to say when the pressure on a nerve tract is sufficient to abolish sensory conduction. In the case of fracture dislocation the lesion was acute, and conduction was absolutely abolished in the roots which formed the upper limit of lesion. Thus the difference in the degree of impairment of function of the highest root involved in the two cases may explain the difference in the height of the anæsthesia. It seems possible in any case to draw more certain and reliable deductions from the case of fracture dislocation, with acute destructive lesion of the roots, than from the case of caries with slow compression of the roots.

It is interesting to note that-as appears the rule in lesions of the cord (cf. Thorburn, ${ }^{7}$ Starr, ${ }^{11}$ Bramwell, ${ }^{12}$ Foggie ${ }^{13}$ )- the extent of total analgesia and thermo-anæsthesia was greater than that of total anæsthesia, and that the limits of the former were more sharply defined than the limits of the latter. There was a sharp line separating the region where the sensations of pain and temperature were abolished from the region where these sensations were intact; the upper limit of total anæsthesia was also fairly sharp, but above this there was a zone of partial anæsthesia, gradually shading off. Such "disassociated" distribution of the sensory disturb ances is regarded by Bramwell as strongly in favour of a cord lesion as against a root lesion, and the greater sharpness of the limits of, and the greater extent of analgesia and thermoanæsthesia as compared with anæsthesia, have led Head to conclude that the mechanism for the sensation of touch in the various spinal segments must overlap, while that for the sensations of pain and temperature does not overlap, at any rate to the same extent. The case of J.S. would seem to show that the same may hold good of spinal roots, although Sherrington, in his experiments on the posterior roots, apparently found the root areas of tactile and painful sensation identical.

The higher limit of the anæsthesia on the right side in Fig. 1, as compared with the condition noted earlier, may have been due to more complete abolition of conduction in the right eleventh root by the growth of callus. I have not found it possible to decide whether the degeneration in that root, as shown by sections, is more recent than in the other parts affected, but the increase in the height of the anæsthesia and the late appearance of a girdle-like pain on the right side a little below the level of the umbilicus suggest that an active process, such as callus formation would readily account for, was at work.
So far we have considered the upper limit of lesion, and it is chiefly with regard to it that the case of $J$. S. appears instructive. In order to determine the lower limit one had to consider the extent downwards through which the central functions of the cord, especially the reflexes and muscular nutrition, were abolished. The exact significance of the complete flaccidity of the leg muscles and of the abolition of the reflexes (knee-jerk, plantar, cremasteric) was doubtful at the onset. There is still difference of opinion as to the effect of a complete transverse lesion of the cord on the state of the reflexes and muscles supplied by the cord below the lesion. The old view was that there was a spastic condition of the muscles and increase of reflexes; this is certainly the rule in a partial lesion of the cord. Bastian's ${ }^{14}$ view, however, which is supported by many clinical observations (for example, that of Bruns), ${ }^{15}$ is that ivjuries causing total interruption of the cord are accompanied by flaccid paralysis and absence of reflexes in the parts below; according to Oppenheim ${ }^{2}$ this is "the rule." Gowers ${ }^{3}$ still adheres to his old opinion that disease above the lumbar enlargement causes per $8 e$ no persistent loss of reflex action in the legs, and that, where this exists, it is usually due to a descending myelitis, or, exceptionally, to the specially irritative character of the descending degeneration in the pyramidal tracts. No other explanation than that of Bastian seems to me to explain clinical facts satisfactorily. In the case of $J$. $\delta$. the rapid wasting of the leg muscles and their loss of faradic excitability roused the suspicion that there was grave destruction of the lumbar enlargement, and that this explained the complete muscular flaccidity and loss of reflexes in the legs. The lower limit of this acute destruction was not quite clear; the fact that the glutei muscles and all the muscles below the knees shared in the rapid wasting and loss of faradic excitability pointed to the lesion extending at least as low as the upper two sacral segments. The centres concerned with the musculature of the bladder and rect um were also evidently affected; these are located in the lower sacral segments of the cord, third and fourth (Oppenheim, Head), fourth and fifth (Bramwell). As in the case of the tendon reflexes, so with Jegard to the bladder and rectum, there is difference of opinion as to the effect of a total transverse lesion of the cord higher up; the usual view is that, where the lesion is distinctly above the centres for the bladder and rectum, there is reflex incontinence, but it has been more recently asserted that this reflex emptying of the bladder and rectum may fail. In the case of J. S., the condition for about two months from the time of injury was one of reflex incontinence of urine; the fact, however, that from the very onset the bladder was never emptied by the reflex gush pointed to weakness of the detrusor action, and made it pro bable that the corresponding centre was partially affected. This was confirmed at the necropsy, as there was evidently much compression of the whole sacral cord-from the epidural hæmorrhage and the longitudinal fracture of the bodies of the vertebre-and the anterior sacral roots were found to be considerably degenerated. The condition of the bladder altered later; its capacity diminished very markedly, and simple incontinence developed; this may have been due, partly at least, to the local condition of cystitis, but it may also have been partly caused by secondary changes, the result of the compression, and probably myelitic in character, affecting the lower sacral segments, and it is possible that the contracted condition of the bladder was due to detrusor spasm, just as retention is not rarely due to sphincter spasm.

I desire in conclusion to express my gratitude to Professor. Ogston for giving me the opportunity of observing the course of this case; to Professor Hamilton for allowing me to examine it pathologically; and to Dr. J. Stewart Milne, with out whose help the record of the case would have been. much less complete.

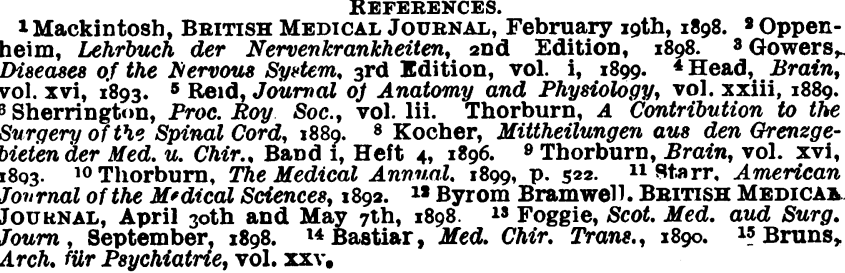

1 Mackintosh, British Medical JoURNAL, February 19th, 1898. ${ }^{2}$ Oppenheim, Lehrbuch der Nervenkrankheiten, and Edition, 1898. vol. xvi, 1893. 5 Re1d, Journal of Anatomy and Physiology, vol. xxiii, 1889. 6 Sherrington, Proc. Roy. Soc., vol. lii. Thorburn, A Contribution to the 1893. 10 Thorburn, The Medical Annual. 1899, p. 522. 11 starr, American Journal of the Medical Sciences, 1892 . 12 Byrom Bramwell. BRITISH MEDICA Journ, September, 1898 . 14 